\title{
Workplace interventions for common mental disorders: a systematic meta-review
}

\author{
S. Joyce ${ }^{1}$, M. Modini ${ }^{1}$, H. Christensen ${ }^{2}$, A. Mykletun ${ }^{3,4,5}$, R. Bryant ${ }^{6}$, P. B. Mitchell ${ }^{1,2}$ and \\ S. B. Harvey ${ }^{1,2,7 *}$ \\ ${ }^{1}$ School of Psychiatry, University of New South Wales, Sydney, NSW, Australia \\ ${ }^{2}$ Black Dog Institute, Sydney, NSW, Australia \\ ${ }^{3}$ Norwegian Institute of Public Health, University of Bergen, Norway \\ ${ }^{4}$ University of Tromsø, Department of Community Medicine, Tromsø, Norway \\ ${ }^{5}$ Competence Centre for Work and Mental Health, Bodø University Hospital, Bodø, Norway \\ ${ }^{6}$ School of Psychology, University of New South Wales, Sydney, NSW, Australia \\ ${ }^{7}$ St George Hospital, Sydney, NSW, Australia
}

\begin{abstract}
Depression and anxiety disorders are the leading cause of sickness absence and long-term work incapacity in most developed countries. The present study aimed to carry out a systematic meta-review examining the effectiveness of workplace mental health interventions, defined as any intervention that a workplace may either initiate or facilitate that aims to prevent, treat or rehabilitate a worker with a diagnosis of depression, anxiety or both. Relevant reviews were identified via a detailed systematic search of academic and grey literature databases. All articles were subjected to a rigorous quality appraisal using the AMSTAR assessment. Of the 5179 articles identified, 140 studies met the inclusion criteria, of which 20 were deemed to be of moderate or high quality. Together, these reviews analysed 481 primary research studies. Moderate evidence was identified for two primary prevention interventions; enhancing employee control and promoting physical activity. Stronger evidence was found for CBT-based stress management although less evidence was found for other secondary prevention interventions, such as counselling. Strong evidence was also found against the routine use of debriefing following trauma. Tertiary interventions with a specific focus on work, such as exposure therapy and CBTbased and problem-focused return-to-work programmes, had a strong evidence base for improving symptomology and a moderate evidence base for improving occupational outcomes. Overall, these findings demonstrate there are empirically supported interventions that workplaces can utilize to aid in the prevention of common mental illness as well as facilitating the recovery of employees diagnosed with depression and/or anxiety.
\end{abstract}

Received 9 May 2015; Revised 9 October 2015; Accepted 15 October 2015; First published online 1 December 2015

Key words: Anxiety, depression, intervention, mental disorder, mental health, work, work stress.

\section{Introduction}

Mental health is an increasingly important topic in the workplace with common mental health disorders, most notably depression and anxiety, now recognized as the leading cause of sickness absence and long-term work disability in most developed countries (Moncrieff \& Pomerleau, 2000; Shiels et al. 2004; Black, 2008; Harvey et al. 2009; Cattrell et al. 2011; Murray et al. 2012). The majority of common mental health conditions are treatable and in some cases preventable (Harvey \& Henderson, 2009; Mykletun \& Harvey, 2012). However, in spite of this, depression and anxiety continue to create significant economic, social and personal costs to employees, employers and society (National Occupational Health and Safety Commission, 2003;

* Address for correspondence to: Dr S. B. Harvey, School of Psychiatry, University of New South Wales, Black Dog Institute Building, Hospital Rd, Randwick, NSW 2031, Australia.

(Email: s.harvey@unsw.edu.au)
Knudsen et al. 2010, 2012, 2013; Harvey et al. 2011). Given these rising costs, it is not surprising that many policy makers view workplace mental health as a major public health issue and are seeking advice on the types of interventions that may be effective.

Despite the size and importance of the problem, there is remarkably limited consensus about the occupational effectiveness of various mental health interventions (Henderson et al. 2011). The majority of treatment trials for depression and anxiety disorders are focused on symptom reduction, with relatively few reporting separate occupational outcomes, in spite of the evidence that occupational recovery may follow a separate course to any symptomatic improvement (Timbie et al. 2006). As a result, it cannot be assumed that standard mental health interventions will be effective in altering occupational outcomes. In addition, there is an expansive body of research identifying a range of important work factors that may impact employee mental health, including psychosocial risk factors (such as job demands, job control, social 
support, organizational justice), perceived job dissatisfaction, organizational change, job insecurity and employment status (Stansfeld \& Candy, 2006; Netterstrom et al. 2008; Nieuwenhuijsen et al. 2010; Ndjaboue et al. 2012). An organization hoping to improve the mental health of its employees may attempt to minimize these established risk factors. As such, workplace interventions for common mental disorders may consist of a combination of facilitating standard clinical treatments together with more specific workplace interventions.

Public health interventions are often classified as primary, secondary or tertiary prevention (Lamontagne et al. 2007; Bhui et al. 2012). Primary prevention interventions are proactive and aim to prevent exposure to a known risk factor or to enhance an individual's tolerance or resilience. The U.S. Preventive Services Task Force (USPSTF, 2008) define secondary prevention interventions as those that identify and treat asymptomatic persons who have already developed risk factors or preclinical disease but in whom the condition has not become clinically apparent'. These secondary approaches typically include both early detection and early treatment with the aim of reducing the severity or duration of symptoms and to halt or slow the further development of more serious and potentially disabling conditions (USPSTF, 2008). Finally, tertiary prevention interventions aim to treat and manage an existing diagnosed condition and to minimize its impact on daily functioning through approaches such as rehabilitation, relapse prevention and by providing access to resources and support (USPSTF, 2008). While a large number of published systematic reviews have focused on various individual interventions for workplace mental health, the relative effectiveness of each approach remains unclear. The purpose of the present meta-review is to systematically examine and synthesize the research evidence regarding the effectiveness of primary, secondary and tertiary workplace mental health interventions for anxiety and depression disorders.

In this study we define a workplace mental health intervention as broadly as possible. We include any intervention that a workplace may either initiate or facilitate that aims to prevent, treat or rehabilitate a worker with a diagnosis of depression, anxiety or both. This definition encompasses a wide range of primary, secondary and tertiary prevention approaches aimed at anxiety and depression within the workplace, for example, mental health education seminars, screening, employee assistance programmes and stressmanagement interventions. Interventions that are not conducted 'on site' or within the workplace but have a work-related component or require facilitation of the workplace are also considered, for example counselling addressing work-related risk factors and individual cognitive therapy with a specific focus on
RTW. As noted above, historically, the efficacy of mental health interventions has been assessed only in terms of symptom alleviation. However, the present review will examine intervention efficacy in terms of both symptom reduction and occupational outcomes, for example improvements in sickness absence, RTW, presenteeism and work productivity. To the best of our knowledge, this is the first meta-review that considers the entire field of academic research relating to workrelated mental health interventions.

\section{Method}

\section{Search strategy}

A meta-review is a method of systematically appraising the results of existing reviews (Ryan et al. 2009). Systematic searches were conducted in Medline, PsycInfo and EMBASE as well as Cochrane Collaboration Summaries. An extensive range of subject headings and keywords combining mental health, work and review were tailored for each database, as demonstrated in Supplementary Table S1. To reduce publication bias, grey literature was also systematically searched via the literature database 'Open Grey' using several keywords including mental health, depression, anxiety work, job and occupation. In addition, subject-matter experts were contacted with a request for any reviews that they thought may be relevant to our study. The reference lists of all the included reviews were examined to identify any reviews that had not been identified.

\section{Inclusion and exclusion criteria}

The criteria used for inclusion in this meta-review were:

(a) paper considered mental disorder, in particular depression and/or anxiety disorders and;

(b) the role of work and workplace interventions were considered and;

(c) was a literature review, systematic review or meta-analyses and;

(d) published in the English language and;

(e) published after 1 January 1990.

Papers that only considered volunteer work or which focused exclusively on a single occupational group were excluded from this review.

\section{Selection process}

Two researchers (M.M. and N.Y.) independently analysed each title and abstract in order to exclude reviews that did not meet inclusion criteria. The full texts of the remaining studies were similarly analysed to ascertain their relevance. In order to achieve consensus, any disagreement about a study's inclusion at either stage was 
referred to a third senior researcher (S.B.H.) for consideration.

\section{Appraisal of quality}

In order to maintain methodological rigour in the meta-review, a measurement tool for the assessment of multiple systematic reviews, the AMSTAR (Shea et al. 2007b) was employed to assess the methodological quality of each review selected for inclusion. The checklist consists of 11 questions with one mark given for a 'yes' response and zero marks for a 'no', 'can't answer', and 'not applicable' response. Questions aim to examine methodological issues such as: whether a systematic literature search was carried out, and whether the scientific quality of included studies was considered when formulating conclusions. A score of 0-4 reflects low-quality research, 5-8 moderate and 9-11 high quality. Given that this tool comprises questions specific to meta-analysis (questions 9 and 10), it was decided that reviews without a meta-analysis would have adjusted cut-off scores to reflect the fact that they could not receive points on these two questions. For systematic reviews, a score of 0-3 was deemed low quality, 4-7 moderate and 89 high quality. The AMSTAR has been shown to have excellent reliability $\left(R^{2}=0.96\right)$ and construct validity (Shea et al. 2007a). Two authors (M.M. and S.J.) independently assessed the quality of each included review using the AMSTAR. When overall quality assessment scores differed between the authors, agreement was reached on the basis of discussion.

The AMSTAR score was then considered together with the type of primary research studies included in each review, to produce a summary statement of the level of evidence for each intervention considered. We adopted a modified version of the Royal College of General Practitioners (RCGP) clinical guidelines, which comprises four categories of evidence; strong, moderate, limited/contradictory and unknown. The definitions used for each of these categories are provided in Table 1. Two levels of evidence were assigned to each intervention. The first level focused on the intervention's efficacy in reducing anxiety and depression symptomology. The second level of evidence focused on the intervention's efficacy at improving occupational outcomes.

\section{Results}

The initial systematic search identified 5179 reviews potential references. Of these, 140 met the inclusion criteria and were reviewed in detail. Twenty review studies met the quality assessment criteria, 18 of which were deemed to be of moderate quality with two studies rated as high quality. Together, these reviews
Table 1. Descriptions of the levels of evidence used in this meta-review

\begin{tabular}{ll}
\hline Levels of evidence & Definition \\
\hline$\star \star \star$ Strong evidence & $\begin{array}{l}\text { High or moderate quality } \\
\text { systematic reviews/meta-analyses } \\
\text { demonstrating consistent results } \\
\text { from multiple randomized control } \\
\text { trials (RCTs) }\end{array}$ \\
& High or moderate quality \\
& systematic reviews/meta-analyses \\
& demonstrating consistent evidence \\
& from non-RCT intervention trials \\
& or less consistent evidence from \\
& RCTs \\
& Mixed or inconsistent evidence \\
& from multiple low- or moderate \\
c Limited or & quality reviews \\
contradictory & Inconclusive research evidence at \\
evidence & present, but some theoretical \\
$?$ Limited or & support. \\
inconclusive evidence & \\
&
\end{tabular}

analysed 481 primary research studies. The complete study selection process is summarized in Fig. 1, with included reviews outlined in Table 2 . The interventions identified are divided into primary, secondary and tertiary interventions. Table 3 provides the current level of evidence for the use of workplace mental health interventions identified in this review.

It is important to note that in the following sections we classify cognitive behavioural therapy (CBT) as both a secondary prevention intervention and a tertiary prevention intervention. We identified that CBT-based stress management interventions are a secondary prevention intervention as this approach specifically targets workers who have not yet received a diagnosis of anxiety/depression but aims to reduce the likelihood of workers developing these conditions. CBT is also listed as a tertiary prevention intervention due to the use of cognitive behavioural skills in the treatment and rehabilitation of affected workers with an established diagnosis of depression and/or anxiety.

\section{Primary prevention interventions}

Primary preventions interventions are those that aim to reduce the onset of a condition as well as reducing the impact of related risk factors. Eight review studies were included that examined primary prevention interventions (Egan et al. 2007; Kuoppala et al. 2008; Martin et al. 2009; Joyce et al. 2010; Brown et al. 2011; Bhui et al. 2012; Osilla et al. 2012). Interventions identified in these reviews include; increasing employee control, physical activity and workplace health promotion (WHP). 


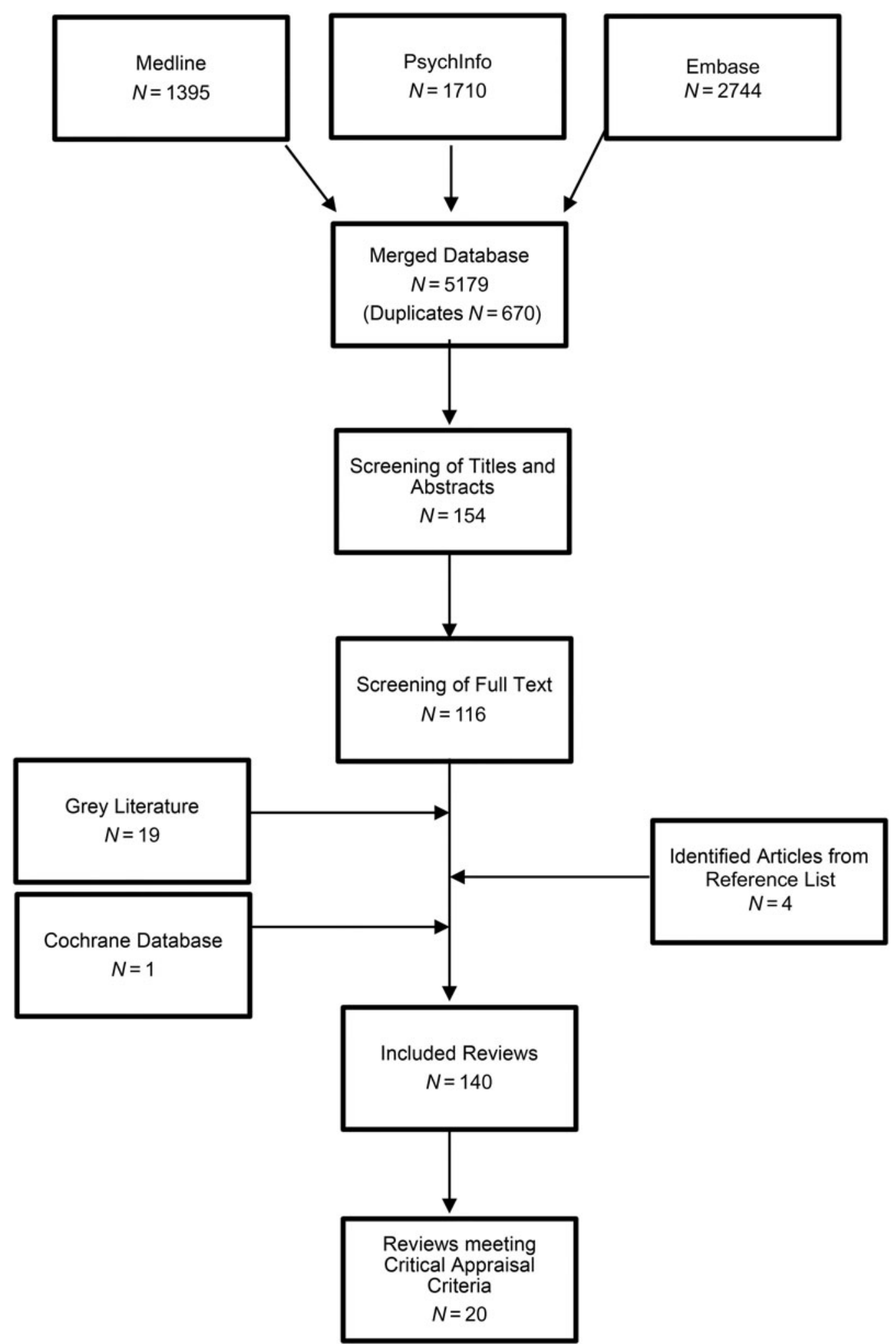

Fig. 1. Flow diagram demonstrating the outcome of the systematic literature search and quality assessment.

\section{Increased employee control}

Symptom reduction: $\star \star$, Occupational outcomes: ?. Two moderate quality reviews assessed interventions that aimed to increase employee control (Egan et al. 2007; Joyce et al. 2010). Egan et al. included studies that evaluated interventions such as problem-solving committees, education workshops and stress reduction 
Table 2. Reviews examining the efficacy of workplace mental health interventions

\begin{tabular}{|c|c|c|c|c|c|}
\hline Author (year) & Interventions examined & Country & $\begin{array}{l}\text { No. of studies } \\
\text { included }\end{array}$ & $\begin{array}{l}\text { Type of } \\
\text { review }\end{array}$ & $\begin{array}{l}\text { Quality } \\
\text { score }\end{array}$ \\
\hline Egan et al. (2007) & Increased employee control & UK & 18 & Systematic & 6 \\
\hline Joyce et al. (2010) & Increased employee control & UK & 10 & Systematic & 7 \\
\hline Brown et al. (2011) & Physical activity & Australia & 20 & Systematic & 4 \\
\hline Kuoppala et al. (2008) & $\begin{array}{l}\text { Physical activity + workplace health } \\
\text { promotion }\end{array}$ & Finland & 46 & Meta-analysis & 6 \\
\hline Bhui et al. (2012) & $\begin{array}{l}\text { Physical activity }+ \text { stress } \\
\text { management programmes }+\mathrm{CBT}\end{array}$ & UK & 23 & Systematic & 5 \\
\hline Osilla et al. (2012) & Workplace health promotion & USA & 33 & Systematic & 4 \\
\hline Martin et al. (2009) & Workplace health promotion & Australia & 22 & Meta-analysis & 5 \\
\hline McLeod (2001) & Counselling & UK & 37 & Systematic & 6 \\
\hline McLeod (2008) & Counselling & UK & 128 & Systematic & 6 \\
\hline Seymour \& Grove (2005) & $\begin{array}{l}\text { Primary, secondary and tertiary } \\
\text { prevention strategies }\end{array}$ & UK & 31 & Systematic & 6 \\
\hline $\begin{array}{l}\text { Richardson \& Rothstein } \\
\text { (2008) }\end{array}$ & $\begin{array}{l}\text { Stress management programmes + } \\
\text { CBT }\end{array}$ & USA & 36 & Meta-analysis & 5 \\
\hline Furlan et al. (2012) & CBT focused & Canada & 12 & Systematic & 7 \\
\hline Pomaki et al. (2012a) & CBT focused & Canada & 8 & Systematic & 7 \\
\hline Bruinvels et al. (2007) & CBT and early RTW & Netherlands & 6 & Meta-analysis & 9 \\
\hline $\begin{array}{l}\text { Van Oostrom et al. } \\
\text { (2009) }\end{array}$ & CBT focused & Netherlands & 1 & Systematic & 10 \\
\hline Noordik et al. (2010) & Exposure therapy & Netherlands & 7 & Meta-analysis & 8 \\
\hline $\begin{array}{l}\text { Stergiopoulos et al. } \\
\text { (2011) }\end{array}$ & Exposure therapy & Canada & 7 & Systematic & 7 \\
\hline $\begin{array}{l}\text { Nieuwenhuijsen et al. } \\
(2008)\end{array}$ & Medication & Netherlands & 11 & Meta-analysis & 8 \\
\hline Corbiere \& Shen (2006) & CBT-based RTW programmes & Canada & 14 & Systematic & 4 \\
\hline ACPMH (2007) & $\begin{array}{l}\text { Debriefing and psychosocial } \\
\text { rehabilitation }\end{array}$ & Australia & 11 & Systematic & 7 \\
\hline
\end{tabular}

CBT, Cognitive behavioural therapy, RTW, return to work.

committees (Egan et al. 2007). Eight of the 18 included studies were controlled (yet not randomized) studies, with the review reporting psychosocial health improvements when employee control improved. Similarly, Joyce $e t$ al. assessed the effects of increased employee control and choice on health outcomes via flexible working interventions (Joyce et al. 2010). This Cochrane Review included 10 controlled before and after studies, although similar to Egan et al.'s review, the authors were unable to identify any randomized controlled trials (RCTs) evaluating these interventions. The review found that flexitime, overtime and fixedterm contracts did not have a significant effect on selfreported psychological health outcomes. However, selfscheduling of shifts by employees and the process of gradual/partial retirement were associated with significant improvements in mental health. Together these findings suggest that workplace interventions that increase employee control may serve to enhance wellbeing and protect against depression and anxiety.
However, it remains unclear as to whether specific occupational factors such as sickness absence are influenced by these interventions.

\section{Physical activity}

Symptom reduction: $\star$, Occupational outcomes: $\star$. The positive effects of physical activity on mental health have been well documented, (Wiles et al. 2007; Hsu et al. 2008; Teychenne et al. 2008) yet the impact of workplace promoted physical activity remains unclear. Three moderate quality reviews were identified that assessed interventions aimed at promoting physical activity (Kuoppala et al. 2008; Brown et al. 2011; Bhui et al. 2012). Brown and colleagues included 13 intervention (eight RCTs and five comparison trials) and seven observational studies which examined the impact of physical activity in the workplace and reported that aerobic exercise and a combination of exercise and relaxation reduced anxiety among employees Brown 
Table 3. The levels of evidence for mental health interventions in the workplace

\begin{tabular}{|c|c|c|c|}
\hline Interventions & $\begin{array}{l}\text { Symptom } \\
\text { reduction }\end{array}$ & $\begin{array}{l}\text { Occupational } \\
\text { outcomes }\end{array}$ & Main conclusions and comments \\
\hline Increased employee control & $\star \star$ & $?$ & $\begin{array}{l}\text { Some interventions, such a problem solving } \\
\text { committees, stress reduction committees, } \\
\text { self-scheduling of shifts and gradual/partial } \\
\text { retirement appear to increase employee control } \\
\text { and reduce mental health symptoms }\end{array}$ \\
\hline Physical activity & $\star \star$ & $\star$ & $\begin{array}{l}\text { May have an effect on employee mental health but } \\
\text { type, amount and intensity of activity required is } \\
\text { unclear. Mixed findings regarding effect on } \\
\text { organizational outcomes. }\end{array}$ \\
\hline Workplace health promotion & $\star$ & $\star$ & $\begin{array}{l}\text { Mixed findings. May have an effect on absenteeism, } \\
\text { but unclear which components most effective }\end{array}$ \\
\hline Screening & $\star$ & $\star$ & $\begin{array}{l}\text { Limited evidence from a small number of RCTs for } \\
\text { the effectiveness of screening in certain work } \\
\text { situations, but only when appropriate detailed } \\
\text { post-screening procedures are in place }\end{array}$ \\
\hline Counselling & $\star$ & $\star$ & $\begin{array}{l}\text { Strong evidence of customer satisfaction, but } \\
\text { objective evidence of benefits remain unclear. } \\
\text { Significant methodological limitations in research }\end{array}$ \\
\hline $\begin{array}{l}\text { Cognitive behavioural therapy } \\
\text { (CBT)-based stress management } \\
\text { interventions (SMI) }\end{array}$ & $\star \star \star$ & ? & $\begin{array}{l}\text { CBT-based stress management interventions } \\
\text { produce individual benefits in terms of reduced } \\
\text { stress and symptoms but this does not appear to } \\
\text { translate to notable improvements in } \\
\text { organizational level outcomes such as absenteeism }\end{array}$ \\
\hline $\begin{array}{l}\text { Psychological debriefing following a } \\
\text { potentially traumatic event in the } \\
\text { workplace }\end{array}$ & $\begin{array}{l}\text { Strong } \\
\text { evidence } \\
\text { against }\end{array}$ & ? & $\begin{array}{l}\text { Psychological debriefing following a traumatic } \\
\text { event unlikely to be of benefit and should not be } \\
\text { offered routinely in the workplace }\end{array}$ \\
\hline $\begin{array}{l}\text { CBT for established depression or } \\
\text { anxiety disorder }\end{array}$ & $\star \star \star$ & $\star \star$ & $\begin{array}{l}\text { Strong evidence that CBT can reduce depression/ } \\
\text { anxiety symptoms but the impact on } \\
\text { organizational outcomes less certain. } \\
\text { Return-to-work programmes which incorporate } \\
\text { CBT and problem-focused strategies have a } \\
\text { positive effect on organizational and individual } \\
\text { outcomes }\end{array}$ \\
\hline $\begin{array}{l}\text { Exposure therapy for established } \\
\text { anxiety disorders and post-traumatic } \\
\text { stress disorder (PTSD) }\end{array}$ & $\star \star \star$ & $\star \star$ & $\begin{array}{l}\text { Exposure therapy can improve symptoms for } \\
\text { individuals who have developed PTSD following } \\
\text { occupation-related injury. Exposure therapy is also } \\
\text { associated with reduced sickness absence and } \\
\text { improved productivity in a range of anxiety } \\
\text { disorders }\end{array}$ \\
\hline Medication & $\star \star \star$ & $?$ & $\begin{array}{l}\text { Strong evidence that medication can reduce } \\
\text { symptoms of established depression and anxiety } \\
\text { disorders. Inconclusive results of the effect of } \\
\text { antidepressants on organizational outcomes for } \\
\text { depressed workers }\end{array}$ \\
\hline
\end{tabular}


studies of high methodological quality and those utilizing valid psychometric measures. In addition, Bhui and colleagues. conducted a meta-review considering a range of interventions in the workplace (Bhui et al. 2012) and concluded that physical activity programmes may reduce absenteeism. A common research limitation in many of the primary studies of exercise programmes in the workplace is the lack of clarity regarding the type, amount and intensity of activity required to produce meaningful benefits. Therefore, while physical activity interventions appear to reduce depressive and anxiety symptoms amongst employees, the impact of such interventions on workrelated factors such as sickness absence require further research.

\section{WHP}

Symptom reduction: $\star$, Occupational outcomes: $\star$. WHP is an overarching intervention addressing both mental and physical health promotion in the workplace. For example, a workplace may promote healthy eating and provide access to mental health services. Three moderate quality reviews, two systematic (Kuoppala et al. 2008; Osilla et al. 2012) and one meta-analysis (Martin et al. 2009), examined the impact of WHP on mental health. All three reviews described mixed results for this broad category of intervention. Kuoppala et al.'s systematic review comprised 46 studies (including 14 RCTs) and found a weak association between WHP and improved mental health and a moderate association between WHP and decreased absenteeism (Kuoppala et al. 2008). This review gave preference to RCTs or cluster-randomized controlled trials, giving strength to their conclusion. Similarly, Martin et al.'s meta-analysis examined a range of WHP interventions and also reported a small positive, effect on mental health outcomes among employees (Martin et al. 2009). However it is unclear which type of WHP produced the most meaningful outcome.

Osilla et al.'s systematic review comprised four studies that examined the mental health benefits of worksite wellness programmes (Osilla et al. 2012). In three of the four studies, these programmes were associated with reduced mental health difficulties. Conversely, the sole RCT in this review did not find any change in employee mental health (Cook et al. 2007). As such, the reviewers concluded that there was insufficient evidence to suggest that WHP improves mental health outcomes among employees.

While WHP interventions have the capacity to target and potentially prevent mental health issues, additional research is needed to establish the effectiveness of this approach and which components produce the most beneficial outcome.

\section{Secondary prevention interventions}

Secondary prevention interventions aim to identify early symptoms and risk factors among workers with the aim of reducing the progression to a disease state. In the workplace setting, secondary prevention interventions often focus on those identified as being exposed to workplace mental health risk factors, such as 'stress' or a traumatic workplace situation. Five review studies were included that addressed secondary prevention interventions in the workplace (McLeod, 2001, 2008; Seymour \& Grove, 2005; Australian Centre for Posttraumatic Mental Health, 2007; Richardson \& Rothstein, 2008; Bhui et al. 2012). Secondary interventions identified in the included reviews were screening, counselling, stress management programmes and posttrauma debriefing.

\section{Workplace screening}

Symptom reduction: $\star$, Occupational outcomes: $\star$. The evidence base for workplace screening was not addressed directly in any of the moderate or high-quality reviews identified. However, the issues surrounding screening in the workplace were discussed in a number of the low-quality reviews, for example Henderson et al.'s (2011) narrative summary. As noted in these reviews, a RCT on screening for depression conducted in a US workforce has found that screening followed by telephone support and care management, resulted in lower self-reported depression scores, higher job retention and more hours worked among employees (Wang et al. 2007). This telephone outreach and care management programme encouraged employees to enter outpatient treatment (psychotherapy and/or antidepressant medication), monitored treatment continuity and attempted to enhance the treatment progress by providing recommendations to treatment providers. Another RCT based in The Netherlands suggested screening patients and providing those with low-level depression symptoms with a minimal contact (mainly self-help) cognitive behavioural intervention resulted in increased work days (Smit et al. 2006). This research has been replicated in Australia in the Work Outcomes Research Cost-Benefit (WORC) Project where the model of early identification and encouragement to seek help has been found to be cost-effective with increased employee wellbeing (Whiteford et al. 2005). However, while these studies were able to demonstrate a benefit for screening, both in terms of symptoms reduction and occupational outcomes in some settings, others have raised concern about the potential risks associated with regular workplace screening (Inbar et al. 1989). Any screening test can produce false positive results, increase distress, heighten stigma and make individuals feel more unwell and focused on their symptoms 
(Solomon et al. 1989). In recent years a number of western militaries have considered the role of predeployment screening in an attempt to identify those at increased risk of mental health problems, however, a recent review found screening in the military had failed to reduce the incidence of psychiatric causalities and potentially good soldiers were rejected because of this process (Jones et al. 2003). Thus, while some concerns about the potential risks remain, there is some limited evidence for the effectiveness of screening in the workforce in certain situations, but only when appropriate and detailed post-screening procedures are in place.

\section{Counselling}

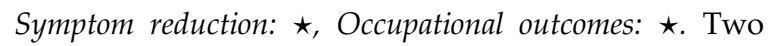
moderate quality reviews from the UK have reported that counselling interventions in the workplace may assist in reducing symptoms of stress, anxiety and depression among employees (McLeod, 2001, 2008). These systematic reviews included 37 and 128 studies, respectively. McLeod's first review concluded that workplace counselling interventions produce a small yet positive impact on work-related outcomes such as job commitment, work functioning and job satisfaction (McLeod, 2001). In addition, McLeod's second review reported that this form of intervention can reduce sickness absence by up to $60 \%$ (McLeod, 2008). These conclusions are compromised by the methodological limitations of the included studies. For example, sample characteristics, the use of control groups and measurement tools varied considerably across studies. The majority of studies focused on client satisfaction, with very few utilizing validated measures of mental health symptoms. Furthermore, the sole RCT included in the initial review, reported no benefit from counselling among employees.

\section{Stress management programmes}

Symptom reduction: $\star \star \star$ (CBT-based programmes), Occupational outcomes: ?. The relationship between perceived 'stress' in the workplace and risk of mental illness is complex with researchers continuing to debate how best to explain this association (Karasek, 1979; Elovainio et al. 2002; Siegrist et al. 2004). The WHO defines work-related stress as 'the response people may have when presented with work demands and pressures that are not matched to their knowledge and abilities and which challenge their ability to cope'. There is evidence that perceived stress can contribute to the development of mental health issues (Stansfeld \& Candy, 2006; Netterstrom et al. 2008; Nieuwenhuijsen et al. 2010). Furthermore, there is a general consensus among mental health researchers and clinicians that long-term pervasive stress coupled with maladaptive coping strategies can place a person at greater risk of developing a mental health condition such as anxiety and depression. It is therefore not surprising that many secondary interventions based in the workplace are aimed at reducing stress as a potential risk factor for these common mental health conditions. A systematic review, of moderate quality, by Seymour and Grove found moderate evidence that workplace stress management programmes may have a modest short-term impact on a range of variables associated with stress (Seymour \& Grove, 2005). This conclusion was based on five studies that mostly comprised of self-selected volunteers with only one true RCT. The interventions reviewed included strategies to acquire problem-solving skills, reduce negative coping style and ways in which to identify stressors, and minimize their impact, at work.

Two other reviews, both of moderate quality, considered the effect of $\mathrm{CBT}$ on reducing stress in the workplace. CBT is based on the underlying rationale that an individual's affect and behaviour is determined by their cognitions with therapy aiming to change the individual's specific misconceptions and maladaptive assumptions (Beck et al. 1979). A meta-review by Bhui and colleagues comprised of 11 meta-analyses and 12 systematic/literature reviews reported that CBT interventions that aimed to reduce workplace stress had larger effect sizes compared to other individual-focused interventions such as relaxation and meditation (Bhui et al. 2012). However this intervention did not influence work-related outcomes such as absenteeism. Similarly, Richardson \& Rothstein (2008) conducted a meta-analysis of 36 studies of stress management interventions, including cognitive behavioural therapies and relaxation techniques. Included studies utilized a random assignment to a treatment and control condition, giving weight to their overall findings. It was concluded that CBT-based stress management interventions produced significant change in terms of symptom reduction yet this did not translate to notable improvements in work-related factors such as absenteeism and productivity (Richardson \& Rothstein, 2008). Examples of cognitive behavioural approaches evaluated in this review include traditional CBT skills, stress inoculation training (SIT), acceptance and commitment therapy (ACT), rational-emotive therapy and online CBT.

\section{Psychological debriefing}

Symptom reduction: $\star \star \star$ (evidence against effectiveness), Occupational outcomes: ?. Psychological debriefing involves a class of interventions delivered immediately following trauma in order to relieve distress and avoid 
long-term psychopathology (Australian Centre for Posttraumatic Mental Health, 2007). It has been suggested that stimulation of emotional ventilation so soon after a traumatic event may actually produce adverse effects (Sijbrandij et al. 2006). A systematic review of 11 adequately controlled trials and RCTs assessing early psychological interventions was identified. It reported that there is unlikely to be any benefits from routine debriefing in preventing the development of post-traumatic stress disorder (PTSD) symptoms or a PTSD diagnosis (Australian Centre for Posttraumatic Mental Health, 2007). The reviewers concluded that debriefing interventions should not be delivered on a routine basis and that if a traumatic incident occurs in the workplace, employees should be offered psychological first aid, emotional and instrumental support and ongoing monitoring.

\section{Tertiary prevention interventions}

Tertiary prevention interventions aim to provide therapy and rehabilitation those who have been formally diagnosed with a mental health condition (Quick et al. 1997). Seven review studies were included that addressed tertiary prevention interventions in the workplace. Tertiary interventions that were identified in the included reviews were cognitive behavioural therapy, exposure therapy and medication.

\section{CBT}

Symptom reduction: $\star \star \star$, Occupational outcomes: $\star \star$. A large body of research evidence supports the application of CBT in the treatment of common mental disorders such as anxiety and depression (NICE, 2004, 2005). As noted earlier, CBT also shows promising outcomes as an early secondary intervention for reducing work-related stress (Richardson \& Rothstein, 2008; Bhui et al. 2012).

Five included reviews examined the effectiveness of CBT interventions for established mental illness in the workplace (Seymour \& Grove, 2005; Corbiere \& Shen, 2006; Bruinvels et al. 2007; van Oostrom et al. 2009; Furlan et al. 2012; Pomaki et al. 2012b). Two moderate quality reviews, and one high-quality Cochrane review, reported that CBT may result in improved outcomes among workers at the individual level (i.e. reduced symptomology) (Bruinvels et al. 2007; van Oostrom et al. 2009; Pomaki et al. 2012a). However, when considering the impact of CBT on occupational outcomes (such as sickness absence) there are mixed findings (van Oostrom et al. 2009; Furlan et al. 2012). One moderate quality systematic review by Pomaki et al. found preliminary evidence that workplace CBT improved work functioning (job performance, productivity) among employees with depression, yet this conclusion was based on a single RCT thus limiting the generalizability of the results (Pomaki et al. 2012a). Another moderate quality systematic review by Furlan et al. comprising 14 studies and one RCT, examined the impact of CBT on organizational outcomes among employees diagnosed with depression or anxiety disorders and concluded that due to the low research quality, no intervention could be recommended as effective in terms of organizational outcomes (Furlan et al. 2012). Similarly, a high-quality Cochrane review by Van Oostrom et al. (2009) concluded that the research evidence for workplace mental health interventions, such as CBT, is of inadequate quality to draw reliable conclusions regarding efficacy.

In contrast, findings from two reviews suggest that CBT may prove more useful in improving occupational outcomes when delivered as part of a return to work (RTW) programme for employees on leave due to psychological injury (Corbiere \& Shen, 2006; Bruinvels et al. 2007). One moderate quality systematic review by Corbiere \& Shen concluded that RTW programmes with a CBT component were usually more effective than treatment as usual for workers with adjustment disorder (Corbiere \& Shen, 2006). Included studies also demonstrated that RTW interventions using CBT led to more favourable outcomes at the individual level, including less psychological distress, improved work satisfaction and reduced depression. Additional support for CBT-focused RTW programmes was reported in a highquality Cochrane review by Bruinevls et al. (2007) which found that CBT may facilitate an earlier RTW, by an average of 2 weeks, among employees with adjustment disorder. More recent studies have suggested the occupational benefits may be even greater problem-focused therapy (PFT), a type of CBT that places much more emphasis on building practical problem-solving skills to facilitate change (Arends et al. 2012).

Taken together, these results suggest that CBT can result in significant improvements in anxiety/depression symptomology. However the impact of CBT on occupational outcomes remains less clear. While there is evidence that CBT can improve occupational outcomes, this appears to be dependent on therapy focusing directly on work matters, such as when part of a formal RTW programme or when emphasizing the development of problem-solving skills directly related to the workplace.

\section{Exposure therapy}

Symptom reduction: $\star \star \star$, Occupational outcomes: $\star \star$. Workplace trauma may be associated with a variety of mental health outcomes, including PTSD (Harvey et al. 2012). The present meta-review identified two studies (Noordik et al. 2010; Stergiopoulos et al. 2011) 
that examined the effectiveness of exposure therapy for work-related anxiety and PTSD across a range of occupations. A meta-analytical review of moderate quality by Noordik et al. included four RCTs and three controlled studies comprised of individuals either reporting anxiety symptoms or individuals diagnosed with PTSD, obsessive compulsive disorder (OCD) or phobias (Noordik et al. 2010). The reviewers concluded that gradual exposure in vivo interventions compared to wait-list control, produced positive outcomes in symptom severity (reduced anxiety symptoms) and work-related factors (increased productivity, reduced sickness absence). Exposure in vivo provided the opportunity for employees to gradually learn how to deal with anxiety-provoking work situations. The reviewers also concluded that exposure in vivo produced similar outcomes to imaginal exposure therapy (aimed at cognitive restructuring and often used in preparation for a real life confrontation with anxietyprovoking situations). Imaginal exposure therapy is less invasive and likely to be more cost-effective from a rehabilitation and RTW programming perspective. While these results show promising outcomes for imaginal exposure therapy and exposure in vivo, the reviewers acknowledge that these conclusions are based on the findings of only two studies, one of which was significantly marred by methodological issues.

Further support for the use of exposure therapy in the workplace was described in a systematic review, of moderate quality, by Stergiopoulos et al. (2011). This review involved seven studies which comprised samples of individuals diagnosed with PTSD. Three of these studies (pre-post design) examined exposurebased treatments for employees with occupationrelated injuries and resulting PTSD. They found that exposure therapy for PTSD resulted in an average RTW rate of $85 \%$ at 6 -month follow-up. Again, these conclusions are interpreted with caution given the limited primary research available (three studies) and lack of suitable control groups.

\section{Medication}

Symptom reduction: $\star \star \star$, Occupational outcomes: ?. Antidepressant medication is well established as a symptomatic treatment for both depression and anxiety disorders (NICE, 2004, 2009). However, only one review was identified that assessed the effectiveness of antidepressant medication as a workplace intervention (Nieuwenhuijsen et al. 2008). This meta-analytical Cochrane review by Nieuwenhuijsen et al. comprised of 11 RCTs and examined the organizational outcome of absenteeism. A particular strength of this review was that it only included studies that utilized validated clinical measurements or the DSM-IV criteria to diagnose depression. The reviewers concluded that selective serotonin reuptake inhibitors (SSRIs), tricyclic antidepressants (TCAs) and serotonin noradrenaline reuptake inhibitors (SNRIs) produced no effect on sickness absence among depressed workers. There was some evidence that antidepressant medication combined with psychodynamic therapy may reduce sickness absence among depressed workers; however, this finding was based on the results of one study. The impact of medication on other work-related outcomes such as presenteeism and productivity remains unclear.

\section{Discussion}

The rising individual, societal and employer costs associated with workplace mental health constitute a major public health issue. To the best of our knowledge, this is the first published meta-review that collectively appraises the range of primary, secondary and tertiary work-related mental health interventions for anxiety and depression. The results demonstrated that a number of these interventions can significantly lessen the burden of anxiety and/or depression in the workplace. To date, much of the focus on workplace mental health has centred around the concept of 'work stress' and the role work may have in precipitating mental ill health (Henderson et al. 2011). The results of this meta-review highlight the positive role work-related interventions could have in maintaining mental health and facilitating recovery from anxiety and/or depression.

More specifically, a number of primary and secondary prevention approaches were identified as demonstrating either moderate or strong efficacy in terms of reducing symptom severity. However, in most of the included reviews, the impact these interventions had on work-related aspects such as absenteeism, presenteeism and productivity remained relatively unexplored. Therefore, while a large body of literature exists regarding the impact of work on mental health, as well as a growing body of research exploring the efficacy of various interventions in alleviating symptomology, the impact on work-related outcomes are often considered separately and in some cases not at all. This has led to an obvious gap in the present research in terms of establishing which work-related mental health interventions produce meaningful outcomes in terms of both symptom reduction and functional improvements in work-related outcomes such as absenteeism and work performance. This is a particular issue is some countries, such as the USA, where employers often pay for healthcare and will therefore be inclined to enquire about the costeffectiveness of treatments from their perspective. 
Consequently, future, studies that aim to develop and evaluate the treatment efficacy of work-related interventions for mental health would benefit from also evaluating and monitoring the work-related outcomes of such approaches.

In terms of primary prevention strategies, we found moderate level evidence supporting two interventions; increasing employee control and promoting physical activity. Primary prevention activities usually aim to either reduce exposure to known risk factors or increase protective or resilience factors (Rose, 1993; Mykletun \& Harvey, 2012). There is a large body of academic literature demonstrating a range of work-based risk factors for mental health, including job strain, psychological demands, job control, social support, organizational justice, perceived job dissatisfaction, organizational change, job insecurity and employment status (Stansfeld \& Candy, 2006; Netterstrom et al. 2008; Nieuwenhuijsen et al. 2010; Ndjaboue et al. 2012). Given the range of identified risk factors, it is surprising that only one workrelated risk factor, job control, has been the subject of multiple reasonable quality intervention trials. While attempting to modify known work-based risk factors makes theoretical sense, in practice such activities require substantial cooperation from employers, who will need to balance the economic costs of changing the way their organizations operate against the potential benefits for their employees. In practice, many workplaces have opted for attempting to enhance their workers' resilience rather than modifying risk factors. Our search did not identify any reviews of sufficient quality examining the effectiveness of workplace resilience training. While there are some promising results emerging (Tan et al. 2014), the overall effectiveness of resilience training needs to be examined in more detail before wide scale use of such interventions can be fully supported. The increasing evidence for the effectiveness of lifestyle modification, specifically increasing levels of physical activity, is in keeping with epidemiological evidence linking increased rates of depression amongst inactive or obese individuals (Teychenne et al. 2008; Rivenes et al. 2009; Harvey et al. 2010). Given that levels of both leisure and workplace physical activity have continued to decrease over recent decades in most developed countries (Foresight, 2007), lifestyle interventions may become an increasingly important part of future workplace mental health prevention strategies.

The majority of published reviews examining secondary prevention interventions focused on individuals who report stress related symptoms. A number of studies have suggested that employees who report high levels of 'work stress' are at a greater risk of developing a range of mental and physical health conditions including, depression, anxiety, hypertension and heart disease (Criniti et al. 2009; LaMontagne et al. 2011). In response to this, there has been an increased level of commercial activity utilizing a wide range of interventions to reduce the impact of work stress. This review identified that many of the more popular approaches to stress management, such as counselling, have limited evidence bases in terms of efficacy. In contrast, CBT-based stress management interventions produced substantial benefits in terms of symptom reduction, but this did not translate to notable improvements in work-related outcomes such as absenteeism and productivity. In terms of secondary prevention following workplace trauma, our findings confirm existing guidance advising against the routine use of either single session or multiple session debriefing (Rose et al. 2002; Wessely et al. 2003; Roberts et al. 2009).

Once depression or anxiety disorders have been diagnosed, there is a range of pharmacological and psychological treatments available which have a strong evidence base for symptom reduction (NICE, 2004, 2005, 2009; Australian Centre for Posttraumatic Mental Health, 2007). However, there is limited evidence that these established symptom-focused interventions had any impact on work-related outcomes, such as absenteeism and productivity. In contrast, tertiary interventions with a specific focus on the workplace, such as exposure therapy, PFT and CBT-based RTW programmes had evidence for improving workrelated outcomes such as absenteeism. These findings add weight to the assertion that symptomatology and occupational functioning are not always closely linked and that standard symptom-focused treatment in isolation may not be adequate (Harvey \& Henderson, 2009). In order to promote functional recovery, the treatment of depression or anxiety disorders requires an integrated approach that incorporates functional goals, such as RTW or exposure to work triggers, from the outset. This is in contrast to the widely held assumption that it is best to allow employees to be fully recovered in terms of their symptoms before RTW is even considered. The need for more integrated management of symptoms and function also raises the question of whether improved case management or better integration between health and vocational rehabilitation sectors could improve patient outcomes (Mykletun \& Harvey, 2012; Harvey et al. 2013).

Within this review, we have tended to focus on the evidence for individual interventions. While clearly defined single interventions may be optimal from a research methodology point of view, such isolated strategies are rarely practical within a workplace setting. In reality most organizations will want to be implementing multiple different interventions at the same time. The systematic review and guidelines around 
workplace interventions published by the British Occupational Health Research Foundation (BOHRF) in 2005 highlighted this point and demonstrated moderate evidence that amongst preventive interventions, multimodal approaches utilizing more than one technique simultaneously, tended to produce better results (Seymour \& Grove, 2005). Subsequent advice for employers has followed this lead in recommending the benefits of multiple, coordinated interventions contributing to an overall strategy for creating more mentally healthy workplaces (Harvey et al. 2014). At present there is limited evidence to guide how single interventions can be best combined, although ensuring a balanced mix of primary, secondary and tertiary interventions would seem a reasonable first step.

The main strengths of this review are the use of meta-review methodology, which enabled coverage of very broad range of topics, the comprehensive search strategy developed and the rigorous quality assessment of each review by two independent researchers. However, there are a number of limitations that must be highlighted. First, a meta-review can only report on literature that has been included in published reviews, meaning some recently published primary research may be excluded. Another limitation was the exclusion of occupation specific reviews, which while ensuring that our findings are generalizable to the general working population, means some workplace sectors (e.g. defence forces) may have specific workplace interventions not captured by our review. A large number of reviews identified by our search strategy were narrative reviews and did not meet the quality criteria required for inclusion into the meta-review. Even amongst the better quality reviews identified, there were a number of key limitations. These include; small sample sizes in treatment groups, lack of random allocation, inconsistent formal diagnostic procedure and a lack of detail defining the nature of interventions such as counselling, WHP or physical activity programmes and limited information regarding how to implement these interventions. Although this review identified many positive findings, it is also important to highlight significant gaps identified. No reviews of adequate quality were identified which examined popular workplace interventions; such as psychological resilience training and screening and there remains a concerning lack of high-quality RCTs across the workplace mental health field.

In conclusion, the problem of mental illness amongst working aged individuals and the associated social and economic costs continues to be a major public health challenge for developed countries. While attempts have been made to address the issue of mental illness in the workplace, it is not clear to what extent this activity has been guided by evidence-based practice. The findings from this meta-review demonstrate that there are now a number of evidence-based primary, secondary and tertiary work-related interventions that can be implemented either within the workplace or can incorporate a specific work-related focus.

\section{Supplementary material}

For supplementary material accompanying this paper visit http://dx.doi.org/10.1017/S0033291715002408.

\section{Acknowledgements}

Funding for this project was provided by Beyond Blue Limited ACN 093865 840, who are an Australian-based mental health charity. The authors remained independent of the funders in their reporting of results. The authors wish to thank Natalia Yee for her assistance in carrying out the systematic search and Nick Arvaniti (Beyondblue) for his assistance throughout the project.

\section{Declaration of Interest}

None.

\section{References}

Arends I, Bruinvels DJ, Rebergen DS, Nieuwenhuijsen K, Madan I, Neumeyer-Gromen A, Bultmann U, Verbeek JH (2012). Interventions to facilitate return to work in adults with adjustment disorders. Cochrane Database of Systematic Reviews 12, 1-115. Art. no. CD006389.

Australian Centre for Posttraumatic Mental Health (2007). Australian Guidelines for the Treatment of Adults with Acute Stress Disorder and Posttraumatic Stress Disorder. ACPMH: Melbourne, Australia.

Beck AT, Rush AJ, Shaw BF, Emery G (1979). Cognitive Therapy of Depression. The Guildford Press: New York.

Bhui KS, Dinos S, Stansfeld SA, White PD (2012). A synthesis of the evidence for managing stress at work: a review of the reviews reporting on anxiety, depression, and absenteeism. Journal of Environmental \& Public Health 2012, 515874.

Black DC (2008). Working for a Healthier Tomorrow. Cross-Government Health, Work and Well-being Programme: UK.

Brown HE, Gilson ND, Burton NW, Brown WJ (2011). Does physical activity impact on presenteeism and other indicators of workplace well-being? Sports Medicine 41, 249-262.

Bruinvels DJ, Rebergen DS, Nieuwenhuijsen K, Madan I, Neumeyer-Gromen A (2007). Return to work interventions for adjustment disorders. Cochrane Database of Systematic Reviews 1, Art. No.: CD006389. 
Cattrell A, Harris EC, Palmer KT, Kim M, Aylward M, Coggon D (2011). Regional trends in awards of incapacity benefit by cause. Occupational Medicine 61, 148-151.

Cook RF, Billings DW, Hersch RK, Back AS, Hendrickson A (2007). A field test of web-based workplace health promotion program to improve dietary practices, reduce stress, and increase physical activity: randomized controlled trial. Journal of Medical Internet Research 9, e17.

Corbiere M, Shen J (2006). A systematic review of psychological return-to-work interventions for people with mental health problems and/or physical injuries. Canadian Journal of Community Mental Health 25, 261-288.

Criniti SM, Aaron E, Levine AB (2009). Using the rapid HIV test to rescreen women in the third trimester of pregnancy. Journal of Midwifery $\mathcal{E}$ Women's Health 54, 492-496.

Egan M, Bambra C, Thomas S, Petticrew M, Whitehead M, Thomson H (2007). The psychosocial and health effects of workplace reorganisation. 1. A systematic review of organizational-level interventions that aim to increase employee control. Journal of Epidemiology and Community Health 61, 945-954.

Elovainio M, Kivimaki M, Vahtera J (2002). Organizational justice: evidence of a new psychosocial predictor of health. American Journal of Public Health 92, 105-108.

Foresight (2007). Tackling Obesities: Future Choices - Project Report. Government Office for Science: London.

Furlan AD, Gnam WH, Carnide N, Irvin E, Amick BC III, DeRango K, McMaster R, Cullen K, Slack T, Brouwer S, Bultmann U (2012). Systematic review of intervention practices for depression in the workplace. Journal of Occupational Rehabilitation 22, 312-321.

Harvey SB, Glozier N, Henderson M, Allaway S, Litchfield P, Holland-Elliott K, Hotopf M (2011). Depression and work performance: an ecological study using web-based screening. Occupational Medicine 61, 209-211.

Harvey SB, Hatch SL, Jones M, Hull L, Jones N, Greenberg N, Dandeker C, Fear NT, Wessely S (2012). The long-term consequences of military deployment: a 5-year cohort study of United Kingdom reservists deployed to Iraq in 2003. American Journal of Epidemiology 176, 1177-1184.

Harvey SB, Henderson M (2009). Occupational psychiatry. Psychiatry 8, 174-178.

Harvey SB, Henderson M, Lelliott P, Hotopf M (2009). Mental health and employment: much work still to be done. British Journal of Psychiatry 194, 201-203.

Harvey SB, Hotopf M, Overland S, Mykletun A (2010). Physical activity and common mental disorders. British Journal of Psychiatry 197, 357-364.

Harvey SB, Joyce S, Tan L, Johnson A, Nguyen H, Modini M, Groth M (2014). Developing a Mentally Healthy Workplace: A Review of the Literature. Black Dog Institute: Sydney.

Harvey SB, Modini M, Christensen H, Glozier N (2013). Severe mental illness and work: what can we do to maximise the employment opportunities for individuals with psychosis? Australian \& New Zealand Journal of Psychiatry 47, 421-424.

Henderson M, Harvey SB, Overland S, Mykletun A, Hotopf M (2011). Work and common psychiatric disorders. Journal of the Royal Society of Medicine 104, 198-207.
Hsu HH, Hoffmann S, Endlich N, Velic A, Schwab A, Weide T, Schlatter E, Pavenstadt H (2008). Mechanisms of angiotensin II signaling on cytoskeleton of podocytes. Journal of Molecular Medicine 86, 1379-1394.

Inbar D, Solomon Z, Aviram U, Spiro S, Kotler M (1989). Officers' attitudes toward combat stress reaction: responsibility, treatment, return to unit, and personal distance. Sep 1989. Military Medicine 154, 480-487.

Jones E, Hyams KC, Wessely S (2003). Screening for vulnerability to psychological disorders in the military: a historical survey. Journal of Medical Screening 10, 40-46.

Joyce K, Pabayo R, Critchley JA, Bambra C (2010). Flexible working conditions and their effects on employee health and wellbeing. Cochrane Database of Systematic Reviews 2, 1-88, Art. no. CD008009.

Karasek RA (1979). Job demands, job decision latitude, and mental strain - implications for job redesign. Administrative Science Quarterly 24, 285-308.

Knudsen AK, Harvey SB, Mykletun A, Overland S (2013). Common mental disorders and long-term sickness absence in a general working population. The Hordaland Health Study. Acta Psychiatrica Scandinavica 127, 287-297.

Knudsen AK, Overland S, Aakvaag HF, Harvey SB, Hotopf M, Mykletun A (2010). Common mental disorders and disability pension award: seven year follow-up of the husk study. Journal of Psychosomatic Research 69, 59-67.

Knudsen AK, Skogen JC, Harvey SB, Stewart R, Hotopf M, Moran P (2012). Personality disorders, common mental disorders and receipt of disability benefits: evidence from the British National Survey of Psychiatric Morbidity. Psychological Medicine 42, 2631-2640.

Kuoppala J, Lamminpaa A, Husman P (2008). Work health promotion, job well-being, and sickness absences - a systematic review and meta-analysis. Journal of Occupational E Environmental Medicine 50, 1216-1227.

Lamontagne AD, Keegal T, Louie AM, Ostry A, Landsbergis PA (2007). A systematic review of the job-stress intervention evaluation literature, 1990-2005. International Journal of Occupational \& Environmental Health 13, 268-280.

LaMontagne A, Sanderson K, Cocker F (2011). Estimating the economic benefits of eliminating job strain as a risk factor for depression. Occupational and Environmental Medicine 68, A3.

Martin A, Sanderson K, Cocker F (2009). Meta-analysis of the effects of health promotion intervention in the workplace on depression and anxiety symptoms. Scandinavian Journal of Work, Environment \& Health 35, 7-18.

McLeod J (2001). Counselling in the Workplace: The Facts. British Association for Counselling \& Psychotherapy: London.

McLeod J (2008). Counselling in the Workplace: A Comprehensive Review of the Research Evidence, 2nd edn. British Association for Counselling \& Psychotherapy: London.

Moncrieff J, Pomerleau J (2000). Trends in sickness benefits in Great Britain and the contribution of mental disorders. Journal of Public Health Medicine 22, 59-67.

Murray CJL, Vos T, Lozano R, Naghavi M (2012). Disability-adjusted life years (DALYs) for 291 diseases and injuries in 21 regions, 1990-2010: a systematic analysis for 
the Global Burden of Disease Study 2010. Lancet 380, 21972223.

Mykletun A, Harvey SB (2012). Prevention of mental disorders: a new era for workplace mental health. Occupational \& Environmental Medicine 69, 868-869.

National Occupational Health and Safety Commission (2003). National Occupational Health and Safety Commission Annual Report 2002-2003. National Occupational Health and Safety Commission: Canberra.

Ndjaboue R, Brisson C, Vezina M (2012). Organisational justice and mental health: a systematic review of prospective studies. Occupational \& Environmental Medicine 69, 694-700.

Netterstrom B, Conrad N, Bech P, Fink P, Olsen O, Rugulies R, Stansfeld S (2008). The relation between work-related psychosocial factors and the development of depression. Epidemiologic Reviews 30, 118-132.

NICE (2004). Anxiety: Management of Anxiety (Panic Disorder, with or without Agoraphobia, and Generalised Anxiety Disorder) in Adults in Primary, Secondary and Community Care).

National Institute for Clinical Excellence: London.

NICE (2005). Post-Traumatic Stress Disorder (PTSD). The Management of PTSD in Adults and Children in Primary and Secondary Care. National Institute for Clinical Excellence: London.

NICE (2009). Depression. The Treatment and Management of Depression in Adults. National Institute for Clinical Excellence: London.

Nieuwenhuijsen K, Bruinvels D, Frings-Dresen M (2010). Psychosocial work environment and stress-related disorders, a systematic review. Occupational Medicine (Oxford) 60, 277-286.

Nieuwenhuijsen K, Bultmann U, Neumeyer-Gromen A, Verhoeven AC, Verbeek JH, van der Feltz-Cornelis CM (2008). Interventions to improve occupational health in depressed people. Cochrane Database of Systematic Reviews 2, 1-45. Art. no. CD006237.

Noordik E, van der Klink JJ, Klingen EF, Nieuwenhuijsen K, van Dijk FJ (2010). Exposure-in-vivo containing interventions to improve work functioning of workers with anxiety disorder: a systematic review. BMC Public Health 10, 598.

Osilla KC, Van Busum K, Schnyer C, Larkin JW, Eibner C, Mattke S (2012). Systematic review of the impact of worksite wellness programs. American Journal of Managed Care 18, e68-e81.

Pomaki G, Franche R-L, Murray E, Khushrushahi N, Lampinen TM (2012a). Workplace-based work disability prevention interventions for workers with common mental health conditions: a review of the literature. Journal of Occupational Rehabilitation 22, 182-195.

Pomaki G, Franche RL, Murray E, Khushrushahi N, Lampinen TM (2012b). Workplace-based work disability prevention interventions for workers with common mental health conditions: a review of the literature. Journal of Occupational Rehabilitation 22, 182-195.

Quick JC, Quick JD, Nelson DL, Hurrell JJ Jr. (1997). Preventive Stress Management in Organizations. American Psychological Association: Washington.
Richardson KM, Rothstein HR (2008). Effects of occupational stress management intervention programs: a meta-analysis. Journal of Occupational Health Psychology 13, 69-93.

Rivenes AC, Harvey SB, Mykletun A (2009). The relationship between abdominal fat, obesity, and common mental disorders: results from the HUNT study. Journal of Psychosomatic Research 66, 269-275.

Roberts NP, Kitchiner NJ, Kenardy J, Bisson J (2009). Multiple session early psychological interventions for the prevention of post-traumatic stress disorder. Cochrane Database of Systematic Reviews 3, 1-44, Art. no. CD006869.

Rose G (1993). The Strategy of Preventive Medicine. Oxford University Press: Oxford.

Rose S, Bisson J, Churchill R, Wessely S (2002). Psychological debriefing for preventing post traumatic stress disorder (PTSD). Cochrane Database of Systematic Reviews 2, 1-46, Art. no. CD000560.

Ryan RE, Kaufman CA, Hill SJ (2009). Building blocks for meta-synthesis: data integration tables for summarising, mapping, and synthesising evidence on interventions for communicating with health consumers. BMC Medical Research Methodology 4, 16.

Seymour L, Grove B (2005). Workplace Interventions for People with Common Mental health Problems. British Occupational Health Research Foundation: London, UK.

Shea BJ, Bouter LM, Peterson J, Boers M, Andersson N, Ortiz Z, Ramsay T, Bai A, Shukla VK, Grimshaw JM (2007a). External validation of a measurement tool to assess systematic reviews (AMSTAR). PLoS ONE 2, e1350.

Shea BJ, Grimshaw JM, Wells GA, Boers M, Andersson N, Hamel C, Porter AC, Tugwell P, Moher D, Bouter LM (2007b). Development of AMSTAR: a measurement tool to assess the methodological quality of systematic reviews. BMC Medical Research Methodology 15, 10.

Shiels C, Gabbay MB, Ford FM (2004). Patient factors associated with duration of certified sickness absence and transition to long-term incapacity. British Journal of General Practice 54, 86-91.

Siegrist J, Starke D, Chandola T, Godin I, Marmot M, Niedhammer I, Peter R (2004). The measurement of effort-reward imbalance at work: European comparisons. Social Science \& Medicine 58, 1483-1499.

Sijbrandij M, Olff M, Reitsma JB, Carlier IVE, Gersons BPR (2006). Emotional or educational debriefing after psychological trauma: randomised controlled trial. British Journal of Psychiatry 189, 150-155.

Smit F, Willemse G, Koopmanschap M, Onrust S, Cuijpers P, Beekman A (2006). Cost-effectiveness of preventing depression in primary care patients: randomised trial. British Journal of Psychiatry 188, 330-336.

Solomon Z, Mikulincer M, Flum H (1989). The implications of life events and social integration in the course of combat-related post-traumatic stress disorder. Social Psychiatry and Psychiatric Epidemiology 24, 41-48.

Stansfeld S, Candy B (2006). Psychosocial work environment and mental health - a meta-analytic review. Scandinavian Journal of Work, Environment and Health 32, 443-462.

Stergiopoulos E, Cimo A, Cheng C, Bonato S, Dewa CS (2011). Interventions to improve work outcomes in 
work-related PTSD: a systematic review. BMC Public Health 11, 838.

Tan L, Wang MJ, Modini M, Joyce S, Mykletun A, Christensen H, Harvey SB (2014). Preventing the development of depression at work: a systematic review and meta-analysis of universal interventions in the workplace. BMC Medicine 9, 74.

Teychenne M, Ball K, Salmon J (2008). Physical activity and likelihood of depression in adults: a review. Preventive Medicine 46, 397-411.

Timbie JW, Horvitz-Lennon M, Frank RG, Normand SLT (2006). A meta-analysis of labor supply effects of interventions for major depressive disorder. Psychiatric Services 57, 212-218.

U.S. Preventive Services Task Force (USPSTF) (2008). Procedure Manual. Agency for Healthcare, Research and Quality (AHRQ) publication, pp. 1-95.

van Oostrom SH, Driessen MT, de Vet HCW, Franche R-L, Schonstein E, Loisel P, van Mechelen W, Anema JR (2009). Workplace interventions for preventing work disability. Cochrane Database of Systematic Reviews 2, 1-64. Art no. CD006955.

Wang PS, Simon GE, Avorn J, Azocar F, Ludman EJ, McCulloch J, Petukhova MZ, Kessler RC (2007). Telephone screening, outreach, and care management for depressed workers and impact on clinical and work productivity outcomes: a randomized controlled trial. Journal of the American Medical Association 298, 1401-1411.

Wessely S, Deahl M, Cannon M, McKenzie K, Sims A (2003). Psychological debriefing is a waste of time. British Journal of Psychiatry 183, 12-14.

Whiteford HA, Sheridan J, Cleary CM, Hilton MF (2005). The work outcomes research cost-benefit (WORC) project: the return on investment for facilitating help seeking behaviour. Australian and New Zealand Journal of Psychiatry 39, A37.

Wiles NJ, Haase AM, Gallacher J, Lawlor DA, Lewis G (2007). Physical activity and common mental disorder: results from the Caerphilly study. American Journal of Epidemiology 165, 946-954. 